\title{
SINGLE-STAGE CHARGE-PUMP VOLTAGE-SOURCE ELECTRONIC BALLAST FOR A 70 W HPS LAMP
}

\author{
José Flávio Dums, Claudinor Bitencourt Nascimento and Arnaldo José Perin \\ INEP - Instituto de Eletrônica de Potência \\ Departamento de Engenharia Elétrica \\ Universidade Federal de Santa Catarina \\ Caixa Postal 5119 \\ 88040-970 - Florianópolis - SC - Brasil
}

\begin{abstract}
In this paper a single-stage charge-pump voltage-source electronic ballast for a $70 \mathrm{~W}$ High Pressure Sodium [HPS] lamp is proposed. Although charge-pump ballasts have already been studied in fluorescent lamp applications, for HPS lamps this topology represents a new research topic. The proposed topology is a combination of a double charge-pump and a half-bridge inverter which share the same switches operating complementary. A microprocessor is used to generate the switching frequency, drive the ballast and to supervise and control the power at the lamp. The proposed ballast presents high power factor and energy efficiency, which is improved by the zero-voltage switching technique. Experimental results obtained on a $70 \mathrm{~W}$ high-pressure sodium lamp are discussed.
\end{abstract}

Keywords - electronic ballast, high-pressure sodium lamp, Power Factor Correction - PFC.

\section{INTRODUCTION}

High pressure sodium lamps cannot be connected directly to the utility line. Since they have a negative impedance characteristic in the desired operating region, these lamps require a ballast which provides a high voltage pulse to startup and another voltage level to operate at. Moreover, the ballast needs to limit the lamp current to prevent its destruction.

Usually electromagnetic ballasts are applied to these lamps but they have some limitations like large size and weight, poor regulation, low power factor [1] and the stroboscopic effect, besides requiring an auxiliary circuit to generate the high voltage start-up pulse.

In order to obtain a compact electronic ballast and eliminate the stroboscopic effect and audible noise, the operating frequency must be raised [2]. Smaller magnetic components are used in this condition which reduces weight and size and the start-up circuit can be inserted into the topology. The main drawback of electronic ballasts is their initial cost with respect to magnetic ballasts, although the energy saving achieved with electronic ballasts make them more economic in the long run [1]. In the case of HPS lamps the energy may be saved considering the possibility of the electronic ballast to dimmer the lamp.

Manuscript received on June 6, 2006. First revision on September 19, 2006 Second revision on November 30, 2006. Recommended by the Editor Richard M. Stephan.
The high-frequency electronic ballasts convert the utility line voltage and frequency into a high-frequency output voltage [3]. Usually they have two stages. The first stage consists of a full-bridge diode rectifier and a power factor correction [PFC] stage. The full-bridge diode rectifier without PFC will drain current with significant harmonics and, therefore, the electronic ballast will operate at a poor power factor. In order to provide a high power factor and generate a dc-link voltage, which is used in the second stage to generate a high frequency ac-voltage, a PFC circuit can be applied. This circuit can be a discontinuous current mode boost whose line current naturally follows the sinusoidal line voltage waveform. However, these two stages increase the cost and the number of components, reducing the efficiency of the electronic ballast. Besides, four power semiconductors devices are conducting current simultaneously. A smaller number of these devices are more desirable in terms of efficiency, reliability, and cost [2], [3].

To avoid these problems, single-stage topologies are more desirable and have been developed in [1-12]. In a single-stage topology, high power factor can be obtained by combining the PFC stage and the inverter stage into a single one with internal low frequency storage. The way to do this is to allow the two stages to share switches in order to simplify the circuit [1]. In this paper, a single-stage PFC ballast is presented and analyzed [13]. The presented electronic ballast employs a different charge-pump topology to correct the power factor. The main contribution of this paper is the use of charge-pump converters for HPS lamp electronic ballasts. This technology was first applied to fluorescent lamp ballasts but its use in HPS lamp electronic ballasts is a recent research topic. This PFC topology is a double charge-pump operating with two complementary switches and limiting input current inductors. This combination duplicates the input current frequency, reducing the magnetic components of the high frequency input filter. Charge-pump capacitors are on the input side and they are also used as a high frequency input filter. The switches are used by the half-bridge inverter. This inverter generates a square wave to supply the lamp located in a LC series resonant filter. The series resonant capacitor is used to eliminate the dc voltage level at the lamp and the series resonant inductor is used to limit the current through the lamp. The advantages of this ballast are that there are only three power semiconductor devices connected in the path from utility line to the ballast output and that all of the switches operate under the same conditions. In the other ballasts, one switch is demanded of more than the others for correcting the power factor [1], [4-8]. 
The proposed topology operates in steady state with a constant duty cycle D $=0.5$ and controlled frequency. Softswitching is necessary to reduce the power losses due to switching and to improve energy efficiency.
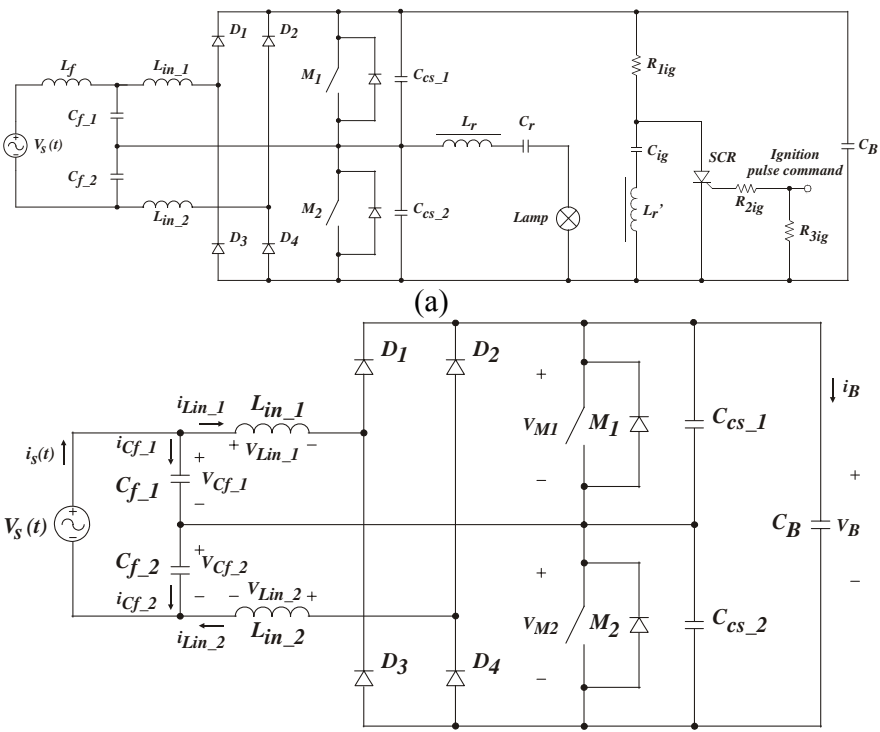

(b)

Fig. 1. Ballast topology. (a) Complete proposed Charge-Pump Voltage-Source. (b) Proposed PFC circuit.

\section{ANALYSIS OF THE PFC STAGE}

The proposed topology is presented in Fig. 1 (a), where the ignition circuit is also included. The ignition pulse is commanded by a microcontroller. The same microcontroller is used to control the output power in a closed loop manner. This structure integrates into one stage a PFC circuit and a half bridge inverter, which supplies the lamp. Although this topology is a single-stage ballast, the input and output functions can be studied separately. The input function is the PFC stage and the circuit that represents this stage is shown in Fig. 1 (b).

To proceed with the PFC analysis, capacitors $C_{f_{-} l}$ and $C_{f_{-} 2}$ will be considered equal and large enough to neglect voltage oscillations over one switching period. In the same manner, $C_{B}$ will be considered large enough to neglect oscillations in dc-link voltage $V_{B}$ and voltage $V_{S}$ will be considered constant during one switching period. In the PFC circuit of Fig. 1 (b), filter inductance $L_{f}$ will be neglected to simplify the analysis and to show that its presence is important for filtering high frequency harmonic distortions in the input current.

The steady-state operation of the PFC circuit during one switching period includes eight stages shown in Fig. 2 whose theoretical waveforms are presented in Fig. 3. All of the components are considered ideal. To guarantee symmetrical operation of the PFC circuit, $L_{i n_{-} l_{1}}$ and $L_{i n_{2} 2}$ need to be equal, as $C_{f_{-} l}$ and $C_{f_{-} 2}$. The design of the circuit is done in a way to guarantee that dc-link voltage $V_{B}$ is larger than peak input voltage $V_{S}$, in order to avoid harmonic distortions in the input current.

In this topology, $i_{C f_{-} 1}$ and $i_{C f_{-} 2}$ are the currents flowing through capacitors $C_{f_{-} 1}$ and $C_{f_{-} 2}$, respectively. $L_{i n_{-} 1}$ and $L_{i n_{-} 2}$ are the input inductors that limit the current of the PFC stage.
$C_{c s_{-} l}$ and $C_{c s_{-} 2}$ are soft-switching capacitors and $C_{B}$ is the dclink capacitor. $M_{1}$ and $M_{2}$ represent the switches of the circuit.

Stage $1\left(\boldsymbol{t}_{0}, \boldsymbol{t}_{1}\right)$ : Before $t_{0}$, switch $M_{2}$ is on and the current through $L_{i n \_} 2$ is increasing. At $t_{0}$, this switch is turned off and a soft-switching transition involving $C_{c s_{-} l}$ and $C_{c s_{-} 2}$ occurs. This stage ends when the voltage across $\bar{C}_{c s_{1}}$ is equal to zero and the voltage across $C_{c s_{2}}$ is equal to the dc-link voltage.

Stage $2\left(t_{1}, t_{2}\right)$ : Once the soft-switching stage is over, the body diode of $M_{1}$ takes over the current. Inductor $L_{\text {in_2 }}$ starts discharging on dc-link capacitor and inductor $L_{i n} 1$ starts charging due to the voltage across $C_{f_{-} l}$. During this stage, $M_{l}$ is turned on in order to avoid switching losses.

Stage $3\left(\boldsymbol{t}_{2}, \boldsymbol{t}_{3}\right)$ : At the moment when $i_{\text {Lin_l }}$ is equal to $i_{\text {Lin } 2}$, the current through switch $M_{1}$ inverts, however $i_{\text {Lin } 1}$ is still increasing and $i_{\text {Lin } 2_{2}}$ is still decreasing.

Stage $4\left(\boldsymbol{t}_{3}, \boldsymbol{t}_{4}\right)$ : This stage starts when $i_{\text {Lin_}_{2}}$ reaches zero. After this, there is only current through $L_{\text {in }}{ }_{1}$, which is still increasing. This stage ends when $M_{1}$ is turned off. At $t_{4}, i_{\text {Lin } 1}$ reaches its peak value $i_{\max }$.

The stages " 5 to 8 " are symmetrical to stages " 1 to 4 ". The difference between them is the charge of the inductor Lin 2 and the discharge of inductor Lin_1. For this reason this four stages will not be discussed at this point, but they are presented in Fig. 2.

As shown in stages " 1 " and " 5 ", there are two softswitching transitions in one switching period. Even so, these soft-switching transition intervals are presented in operating stages they can be neglected. Based on equation (2) it is possible to understand that these intervals are very short when compared to one switching period. Solving (1) for the dc-link voltage and half of $i_{\text {Lin } 1}$ circulating through $C_{c s ~}$, equation (2) can be obtained. The transition interval is represented by $T_{t}$ and capacitors $C_{c s_{-} I}=C_{c s_{-} 2}$.

$$
\begin{gathered}
i_{C s_{-} l}=C_{c s_{-} l} \cdot \frac{\partial V_{C s_{-} l}}{\partial t} \\
T_{t}=\frac{V_{B} \cdot 2 \cdot C_{c s_{-} l}}{i_{\max }}
\end{gathered}
$$

At the first half of the period, current $i_{\text {Lin_l } 1}$ is described by:

$$
i_{\text {Lin_l }}=\frac{V_{S}}{2 \cdot L_{\text {in_l }}} \cdot\left(t-t_{1}\right)
$$

When the switching interval is equal to half of the period the current is at its peak value. This value is represented by:

$$
i_{\text {max }}=\frac{V_{S}}{2 \cdot L_{\text {in_l }}} \cdot \frac{T_{s}}{2}=\frac{V_{S} \cdot T_{s}}{4 \cdot L_{\text {in_l }}}
$$

From "Kirchoff Current Law" [KCL] applied to Fig. 1 (b) it is possible to obtain:

$$
i_{S}=i_{\text {Lin_l } 1}+i_{C f_{-} 1}=i_{L i n \_2}+i_{C f_{-} 2}
$$



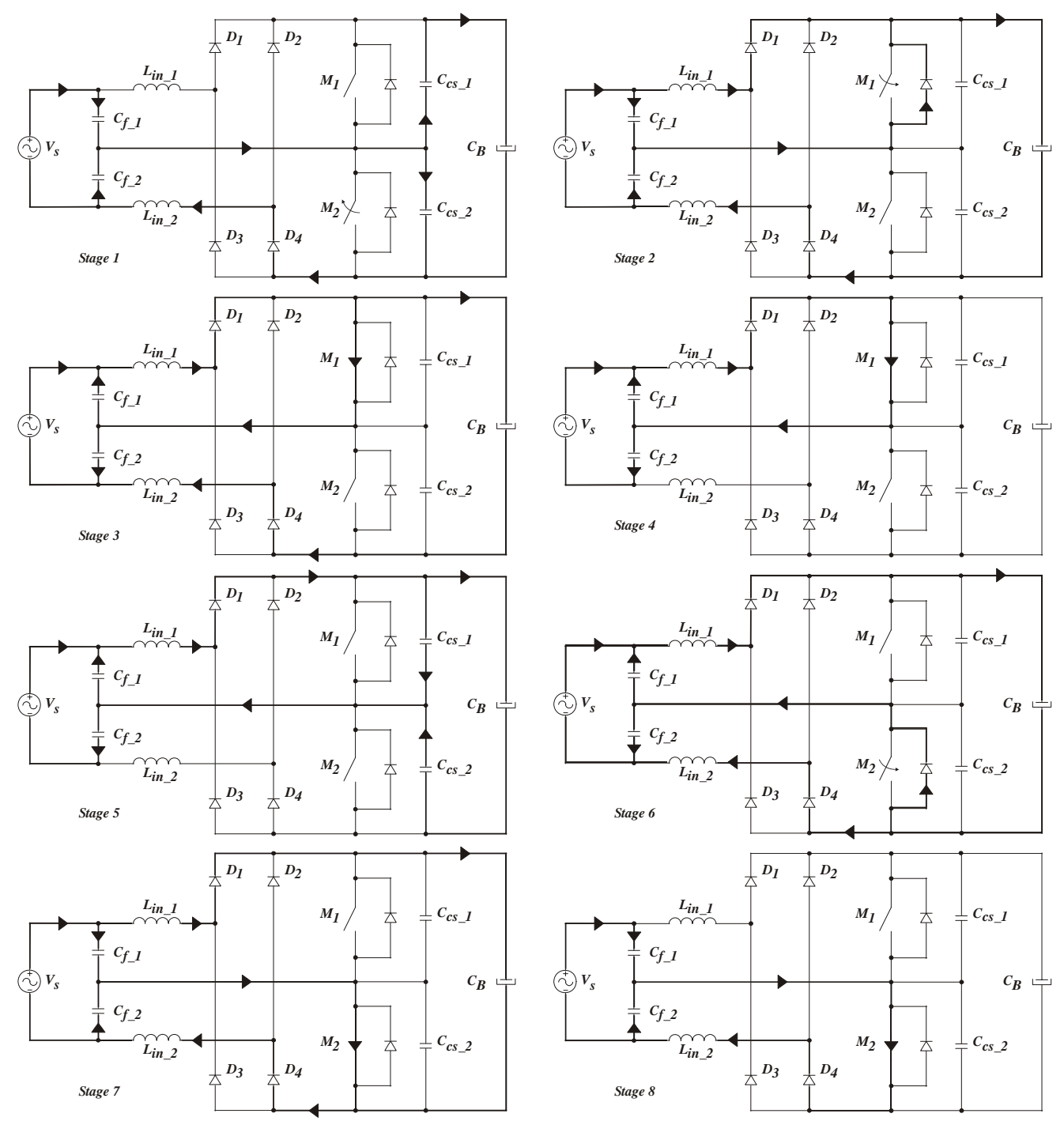

Fig. 2. Operating modes of PFC stage.

Analyzing $i_{C f 1}$ and $i_{C f 2}$ and the voltages across these capacitors in the first half of the period, the currents can be described as:

$i_{C f_{-} 1}=C_{f_{-}} \cdot \frac{\partial V_{C f_{-} 1}}{\partial t}=C_{f_{-} 1} \cdot \frac{\partial\left(V_{S}-V_{C f_{-} 2}\right)}{\partial t}=-C_{f_{-} I} \cdot \frac{\partial V_{C f_{-} 2}}{\partial t}$

Considering that these capacitors have the same value:

$$
i_{C f_{-} 1}=-i_{C f_{-} 2}
$$

From KCL and (6) it is possible to confirm that:

$$
i_{S}=\frac{\left(i_{\text {Lin_l }_{-1}}+i_{C f_{-} 1}\right)+\left(i_{\text {Lin_ }_{-}}+i_{C f_{-} 2}\right)}{2}
$$

Substituting (7) into (8), the input current is described by:

$$
i_{S}=\frac{i_{\text {Lin } 1}+i_{\text {Lin_ } 2}}{2}
$$

Since the charging times of $L_{i n_{-} 1}$ and $L_{i n_{2} 2}$ are different from their discharging times, a high frequency oscillation in the input current appears. This oscillation can be seen in Fig. 3 , however, to simplify the analysis, this high frequency oscillation will be neglected. For this reason, the maximum current in the source can be represented by:

$$
i_{m}=i_{\text {max }}=i_{\text {Lin_l } 1}+i_{\text {Lin_2 }}
$$

And the input current can be approximated by:

$$
i_{S}=\frac{i_{m}}{2}
$$

The source is sinusoidal and is represented by:

$$
V_{S}(t)=V_{S} \cdot \sin (\omega \cdot t)
$$

Substituting (4) and (12) into (11), the equation of the input current is:

$$
i_{S}=\frac{T_{s} \cdot V_{S}}{8 \cdot L_{i n_{-} l}} \cdot \sin (\omega \cdot t)
$$




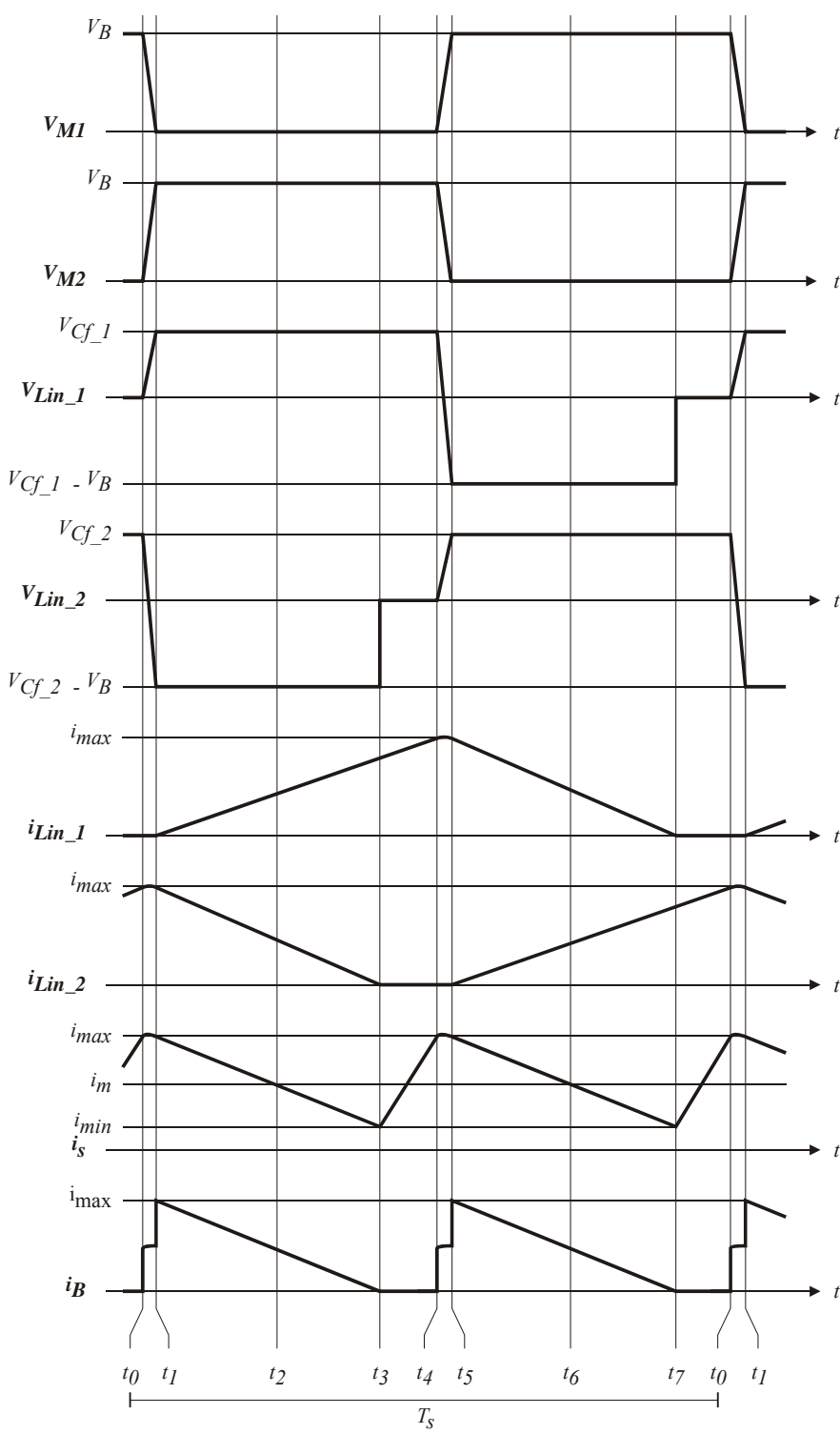

Fig. 3. Theoretical waveforms of the PFC circuit.

The average of the real input power $P_{\text {in }}$ is determined by:

$$
P_{i n}=\frac{1}{\pi} \cdot \int_{0}^{\pi}\left(V_{S} \cdot i_{S}\right) \cdot \partial(\omega \cdot t)=\frac{T_{S} \cdot V_{S}^{2}}{16 \cdot L_{i n_{-} l}}
$$

The power factor $[P F]$ is given by:

$$
P F=\frac{P_{i n}}{V_{S_{-} r m s} \cdot i_{S_{-} r m s}}=\frac{\frac{T_{s} \cdot V_{S}^{2}}{16 \cdot L_{i n_{-} l}}}{\frac{T_{S} \cdot V_{S}}{\sqrt{2}} \cdot \frac{T_{2} \cdot L_{\text {in_l }} l}{8 \cdot \sqrt{2}}}=1
$$

With this result it is possible to see that a high power factor can be obtained when the correct input filter is used to reduce the high frequency current harmonics. It is important to note that the high frequency oscillation in the input current occurs at twice the switching frequency, as shown in Fig. 3. This characteristic provides a smaller inductor for the input filter, reducing weight and size. Inductance $L_{i n_{-} l}$ is designed to operate in PFC situations for the active input power desired at ballast, as follows:

$$
L_{i n_{-} l}=\frac{V_{S}^{2}}{16 \cdot f_{s} \cdot P_{i n}}
$$

According to simulation results, if resonant frequency $\omega_{0}$ is about three-tenths of the switching frequency, unity power factor is obtained. This relation is shown in (17) and input capacitor $C_{f_{-}}$is given by (18).

$$
\begin{gathered}
\alpha=\frac{\omega_{0}}{\omega_{s}}=0.3 \\
C_{f_{-} 1}=\frac{4 \cdot P_{i n}}{\pi^{2} \cdot f_{S} \cdot V_{r}^{2} \cdot \alpha^{2}}
\end{gathered}
$$

\section{HALF-BRIDGE INVERTER}

Although the half-bridge inverter is a well known topology in the technical literature, this paper will approach this structure in a different focus. This study is done in a way to obtain some equations and curves that show the behavior of the power of the lamp during its life and that are able to justify the use of the feedback control system.

In high-frequency operation, the steady-state impedance of the HPS lamp can be considered a resistor, $R_{\text {Lamp }}$. The series resonant network, $L_{r}, C_{r}$ and $R_{\text {Lamp }}$, operates as an inductive load in steady-state. The inverter stage operates above the resonant frequency, achieving zero voltage softswitching turn-on.

Before the start-up of the lamp, its resistance is so high that it can be considered an open circuit. Immediately after start-up, this resistance falls to very low values, almost a short circuit, and starts increasing until reaching its steadystate value, which is obtained after several minutes.

Dc-link capacitor $C_{B}$ is large enough to obtain dc-link voltage $V_{B}$. Dc-blocking capacitor $C_{r}$ is used to block the dc component of the square-wave voltage and prevents the cataphoresis problem at the electrodes of the lamp.

The circuit that represents this inverter is presented in Fig. 4. Its operating stages are presented in Fig. 5 and the main waveforms are shown in Fig. 6, where $V_{G M 1}$ and $V_{G M 2}$ are the drive voltages of switches $M_{1}$ and $M_{2}$, respectively.

Stage $1\left(t_{0}, t_{1}\right)$ : Before $t_{0}, M_{2}$ is conducting the lamp current. At $t_{0}$ this switch is turned off. A commutation stage occurs during which the voltage across $M_{1}$ decreases to zero due to the discharge of $C_{c s} I$ and the voltage across $M_{2}$ increases to dc-link voltage $\bar{V}_{B}$ due to the charging of $C_{c s_{-} 2}$. At $t_{0}$ the current in the lamp is at its negative peak.

Stage $2\left(t_{1}, t_{2}\right)$ : After switching, the body diode of $M_{l}$ conducts the lamp current until it changes its direction. During this stage $M_{1}$ is turned on, avoiding switching losses.

Stage $3\left(t_{2}, t_{3}\right)$ : When the direction of the lamp current changes, $M_{1}$ takes over the current which increases until $t_{3}$ when $M_{1}$ is turned off. At $t_{3}$, the lamp current reaches its positive peak value. 


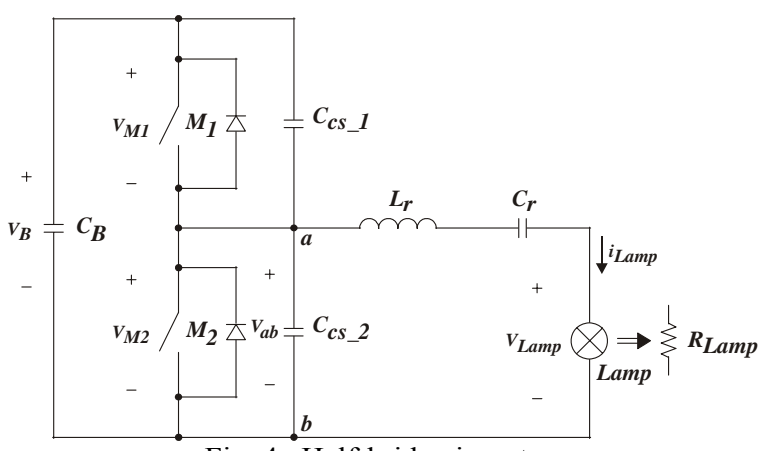

Fig. 4. Half-bridge inverter.

The behaviors of the stages " 4 to 6" are symmetrical to the behavior of the stages " 1 to 3 ". The difference between them is the current direction in the lamp, which make the switch $M_{2}$ assumes this current. For this reason these stages will not be described in this paper, but they are presented in Fig. 5.

From the waveform of $V_{a b}$ in Fig. 6 it is possible to calculate the Fourier series of voltage $V B_{a b}$. This voltage is the one which is applied across the series resonant filter.

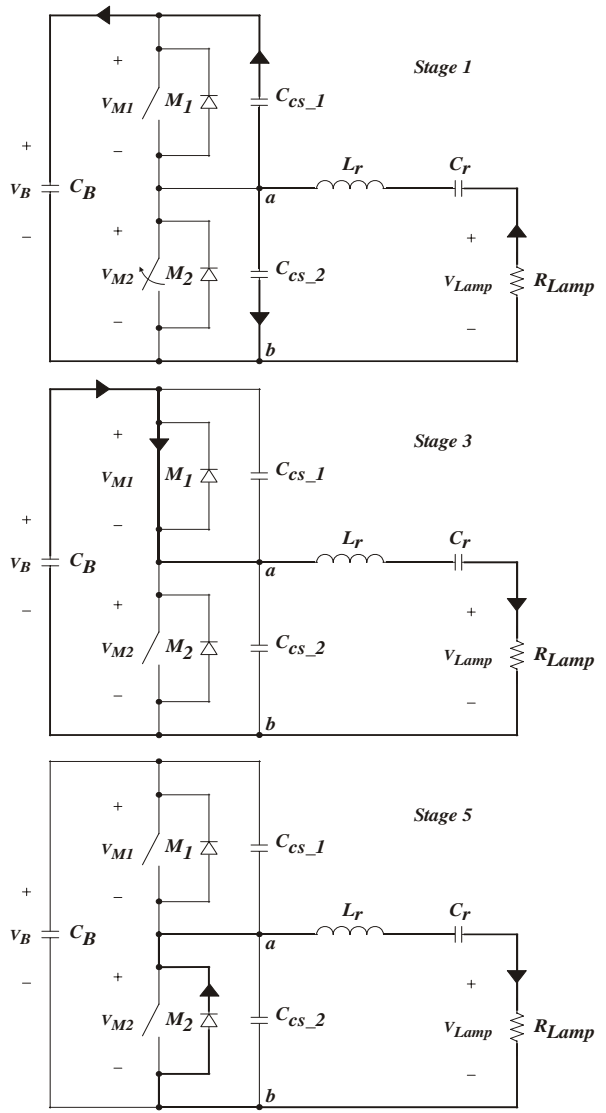

$$
V_{a b}(t)=\frac{V_{B}}{2}+\frac{2 \cdot V_{B}}{\pi} \cdot \sum_{n=1}^{\infty} \frac{1-(-1)^{n}}{2 \cdot n} \cdot \sin \left(n \cdot \omega_{s} \cdot t\right)
$$

In this equation, variable $\omega_{s}$ is the angular switching frequency and the fundamental peak voltage is given by:

$$
V_{a b-p k}=\frac{2 \cdot V_{B}}{\pi}
$$

To simplify the analysis of the circuit, only the RMS value of equation (19) will be considered. This value is indicated by:

$$
V_{a b-r m s}=\frac{V_{B} \cdot \sqrt{2}}{\pi}
$$

From Fig. 4, it is possible to obtain the value of the series resonant filter impedance.

$$
Z=R_{\text {Lamp }}+j \cdot\left(\frac{-1+\omega_{s}^{2} \cdot C_{r} \cdot L_{r}}{\omega_{s} \cdot C_{r}}\right)
$$

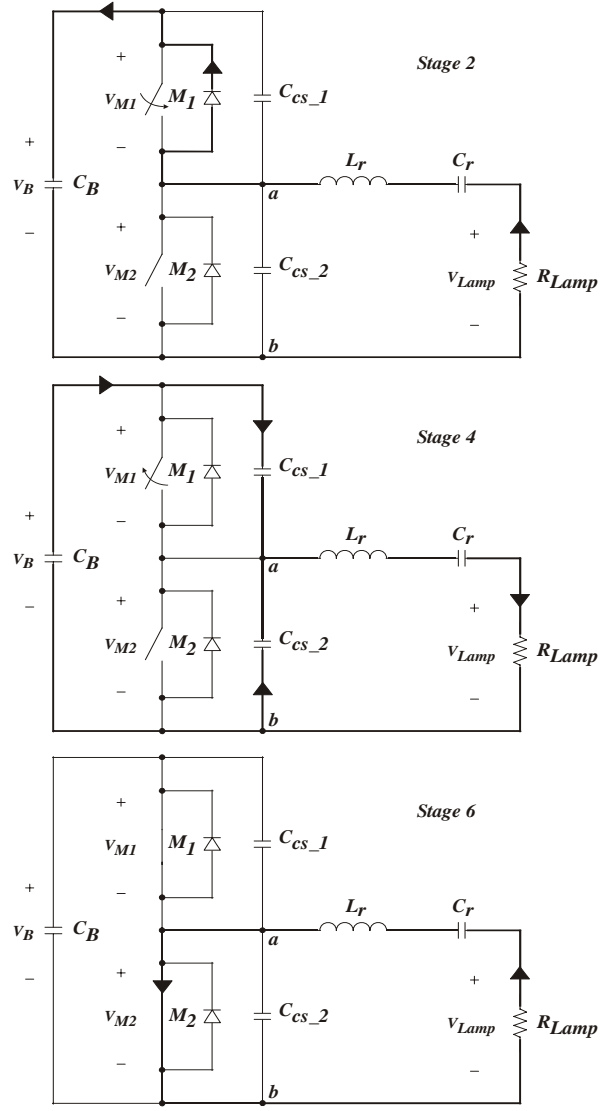

Fig. 5. Operating modes of the half-bridge inverter. 


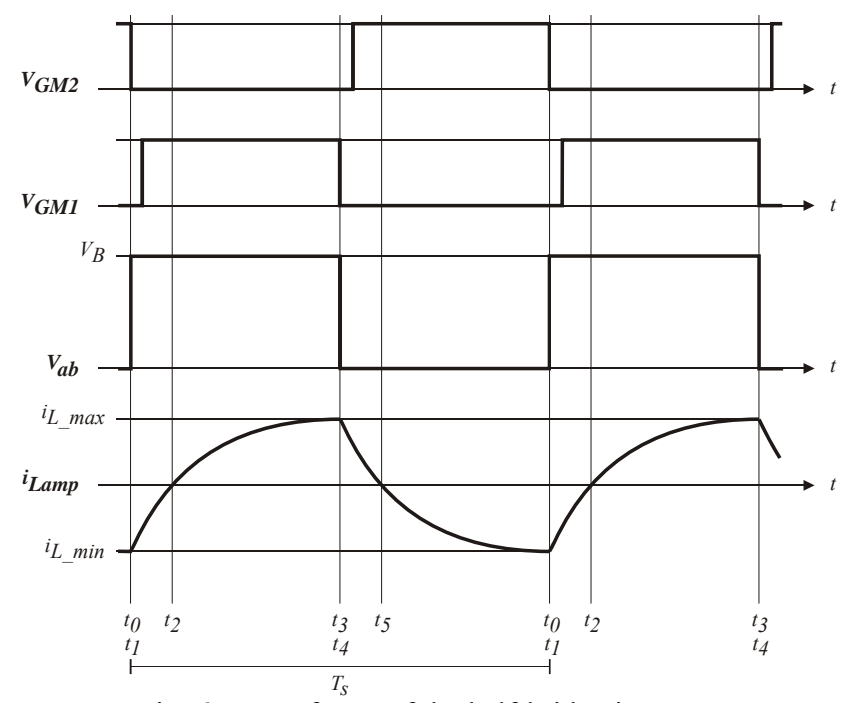

Fig. 6. Waveforms of the half-bridge inverter.

This impedance has a real part and an imaginary one. The phase between fundamental voltage $V_{a b}$ and the current through the series resonant filter is given by:

$$
\phi=\tan ^{-1}\left(\frac{\operatorname{Im}(Z)}{\operatorname{Real}(Z)}\right)=\tan ^{-1}\left(\frac{-1+\omega_{s}^{2} \cdot C_{r} \cdot L_{r}}{\omega_{s} \cdot C_{r} \cdot R_{\text {Lamp }}}\right)
$$

Inductance $L_{r}$ can be written as a function of $R_{\text {Lamp }}, C_{r}$ and phase $\phi$ :

$$
L_{r}=\frac{\omega_{s} \cdot C_{r} \cdot R_{\text {Lamp }} \cdot \tan (\phi)+1}{\omega_{s}^{2} \cdot C_{r}}
$$

The current through the filter can be written as the ratio between voltage $V_{a b}$ and the $L C$ series resonant filter impedance:

$$
I=\frac{V_{a b-r m s}}{Z}
$$

Substituting equations (21), (22) and (24) into (25), the current is determined.

$$
I=\frac{V_{B} \cdot \sqrt{2}}{\pi \cdot R_{\text {Lamp }} \cdot(1+j \cdot \tan (\phi))}
$$

The power of the lamp is determined by:

$$
P=R_{\text {Lamp }} \cdot I^{2}
$$

Replacing (26) in (27) the power equation of the lamp can be obtained as a function of the phase, the lamp resistance and the dc-link voltage:

$$
P=R_{\text {Lamp }} \cdot\left|\frac{V_{B} \cdot \sqrt{2}}{\pi \cdot R_{\text {Lamp }} \cdot(1+j \cdot \tan (\phi))}\right|^{2}
$$

Plotting the result of equation (23), the behavior of the phase angle as a function of the lamp's equivalent resistance can be seen. Fig. 7 (a) shows that, as the lamp ages and its impedance increases, the phase angle decreases.

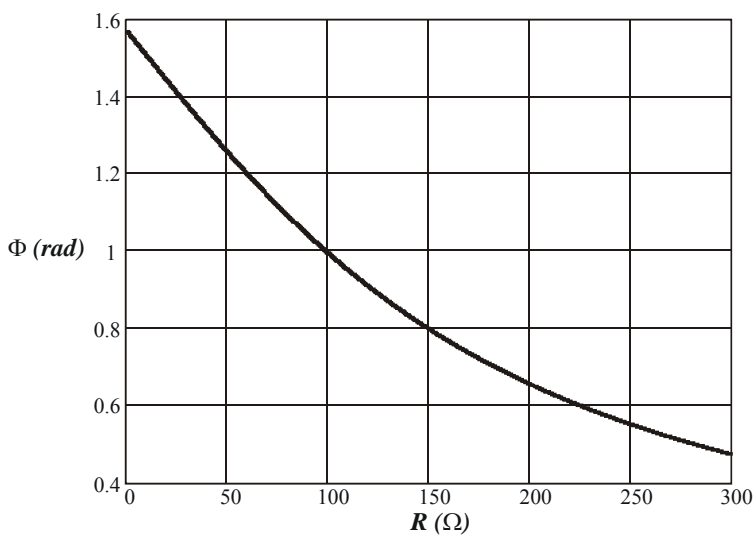

(a)

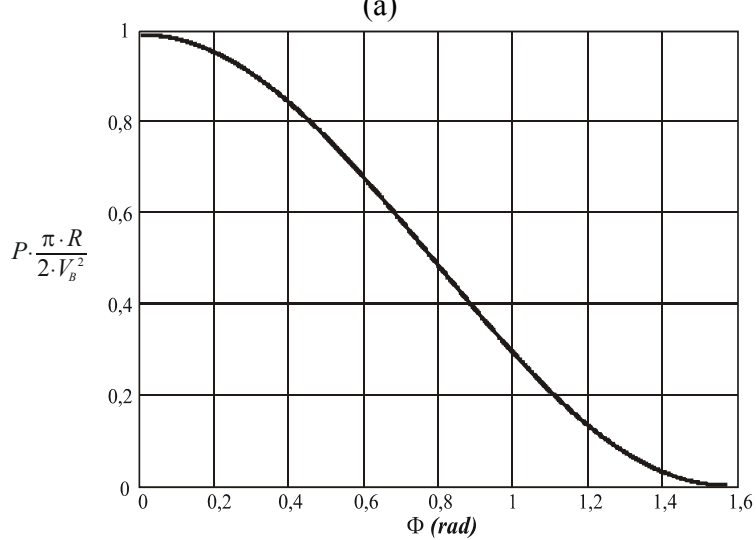

(b)

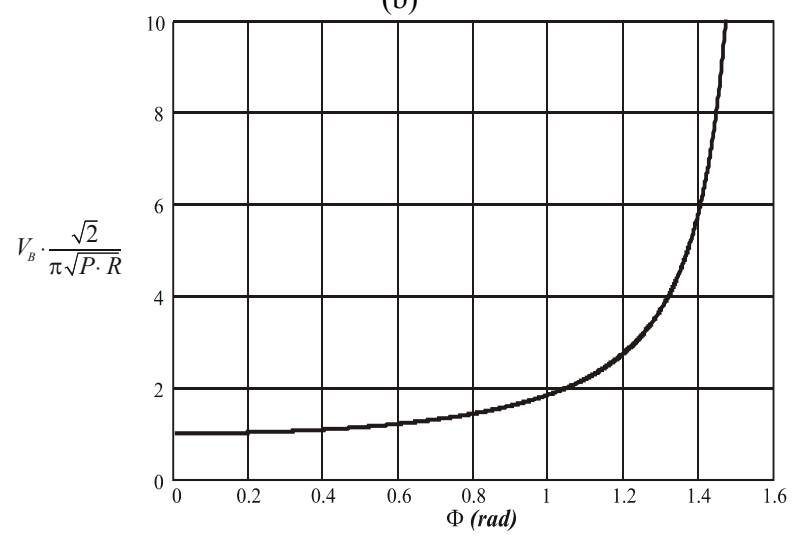

(c)

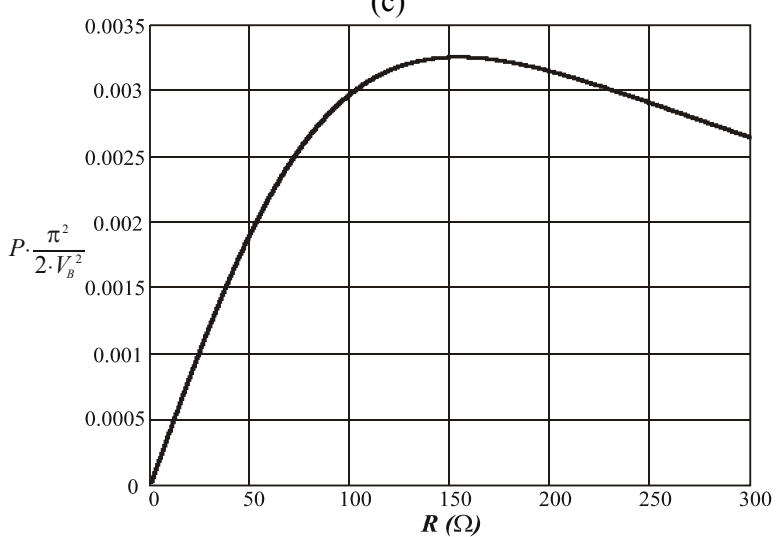

(d)

Fig. 7. Curves. (a) Variation of the phase angle as a function of the lamp's equivalent resistance. (b) Normalized power of the lamp as a function of the phase angle. (c) Normalized dc-link voltage as a function of the phase angle. (d) Normalized lamp power as a function of the lamp's resistance. 
This result is important to understand Fig. 7 (b) which shows the behavior of the normalized power of the lamp as a function of the phase angle. This figure was obtained from equation (28) and shows that as the angle increases, the power of the lamp decreases. In this manner, as the lamp ages, the power of the lamp increases. This behavior shows that a power control system, not showed in this paper must be applied to avoid this effect and provide constant power to the lamp.

Another important result obtained from (28) is shown in Fig. 7 (c). This one presents the normalized behavior of the dc-link voltage as a function of the phase angle. As the lamp ages and the phase angle decreases, the dc-link voltage also decreases. If this voltage decreases and becomes lower than the peak of the input voltage, the power factor will decrease due to the high harmonic distortion in the input current.

To illustrate the power behavior of the lamp throughout its lifetime, Fig. 7 (d) presents the normalized power of the lamp as a function of the lamp's resistance, maintaining constant the switching frequency of the inverter. This curve confirms that if the ballast does not have a control system, the lamp will receive more power than desired throughout its lifetime and, consequently, its life will be reduced.

\section{EXPERIMENTAL RESULTS}

The ballast topology proposed in Fig. 1 (a) was implemented in the laboratory and it was designed for a $70 \mathrm{~W}$ high pressure sodium lamp. The electronic ballast is operated using a microcontroller to generate switch pulses and to control the output power. The feedback control system used hysteresis control, which measured the power of the lamp and regulated the frequency in order to obtain the correct power value.

The system parameters used for this experiment were:

$$
\begin{array}{ll}
V_{S}(t)=220 \cdot \sqrt{2} \cdot \sin (\omega \cdot t) V \quad L_{f}=3 \mathrm{mH} \\
C_{f_{-} l}=C_{f_{-} 2}=82 \eta \mathrm{F} & L_{i n_{-} l}=L_{i n_{-} 2}=1.35 \mathrm{mH} \\
L_{r}=950 \mu \mathrm{H} & C_{r}=22 \eta \mathrm{F} \\
C_{B}=50 \mu \mathrm{F} & \mathrm{D}=0.5
\end{array}
$$

The initial design was done for a switching frequency equal to $50 \mathrm{kHz}$, but this value changes according to the lamp's equivalent resistance during its lifetime and due to variations in the input source voltage. The soft-switching capacitors used in this experiment were the internal drainsource capacitors of the MOSFETs.

Fig. 8 (a) shows input voltage $V_{S}(t)$ and input current $i_{S}(t)$. The measured power factor is 0.995 . Fig. 8 (b) shows current $i_{\text {Lin_l } 1}$ and current $i_{\text {Lin_2 } 2}$. Fig. 8 (c) shows the voltage and the current waveforms of switch $M_{l}$ which were obtained at the peak of the input source voltage. The waveforms in Fig. 8 were obtained with a new lamp and illustrate the behavior of the PFC stage. It is possible to see that the switches commutate under the zero voltage condition, therefore, obtaining low switching losses.

To illustrate the behavior of the half-bridge inverter some waveforms are presented in Fig. 9. In Fig. 9 (a) voltage $V_{\text {Lamp }}$ and current $i_{\text {Lamp }}$ at the peak of input voltage $V_{S}(t)$ are presented showing that the lamp operates like a resistance at high frequency. Fig. 9 (b) presents the low frequency lamp current showing that the crest factor is 1.52 . With the power measured in Fig. 8 (a) and Fig. 9 (b) the efficiency of the ballast results close to $96 \%$. In order to improve the efficiency transistors with very low $\mathrm{R}_{\mathrm{DS} o n}$ (IRF27N60K) were used in this experiment.
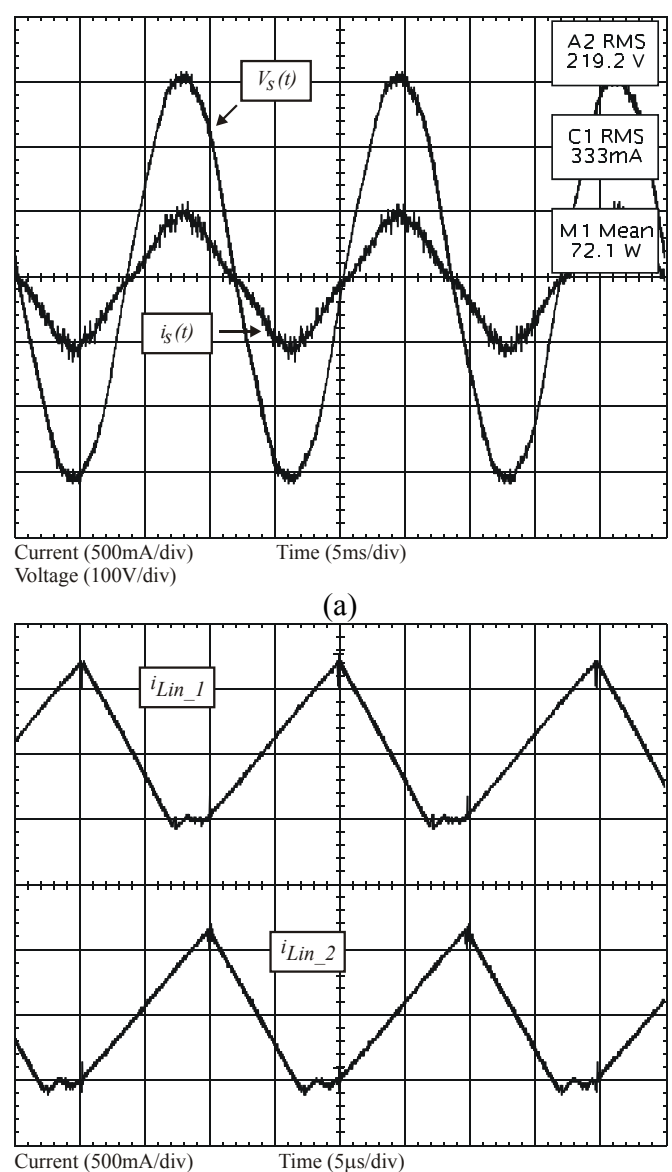

(b)

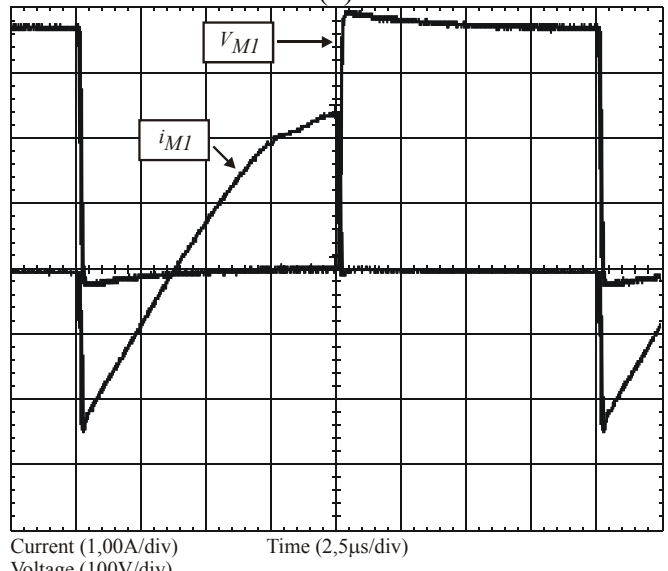

(c)

Fig. 8. Ballast waveforms for a new lamp. (a) Input source voltage and current. (b) Current $\boldsymbol{i}_{\text {Lin_1 }}$ and $\boldsymbol{i}_{\text {Lin_2 }}$. (c) Voltage and current of $M_{1}$.

To show the behavior of the power control system applied to this ballast, Fig. 10 presents the waveforms for an old lamp operated by the same ballast. It is possible to note that the values of the voltage and current of the lamp 
presented in Fig. 10 (a) are different from those shown in Fig. 9 (a) due to the higher equivalent resistance of the lamp. Moreover, the frequencies of these waveforms are different. In Fig. 10 (b) the low frequency current through the lamp is shown. In this case, the crest factor is 1.43 and proves that this value does not change significantly throughout the lamp's lifetime. Comparing the acquisition values of Fig. 9 (b) and Fig. 10 (b) it is possible to see that the measured power of the lamp is still close to the desired lamp power, validating the feedback control system applied to this ballast.

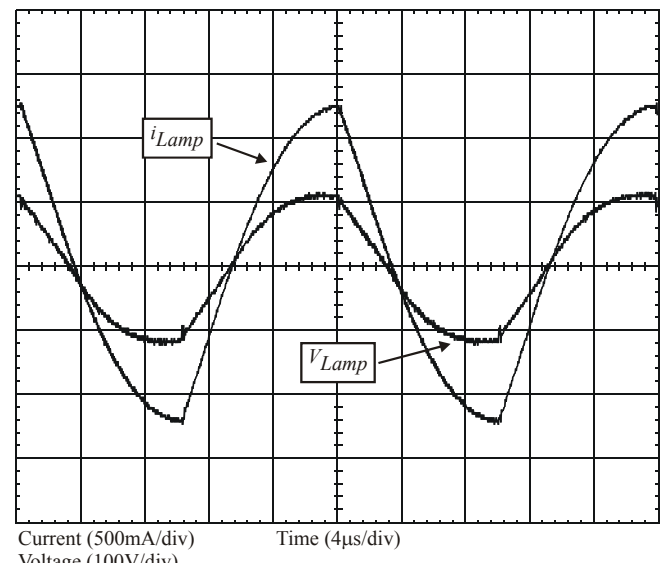

(a)

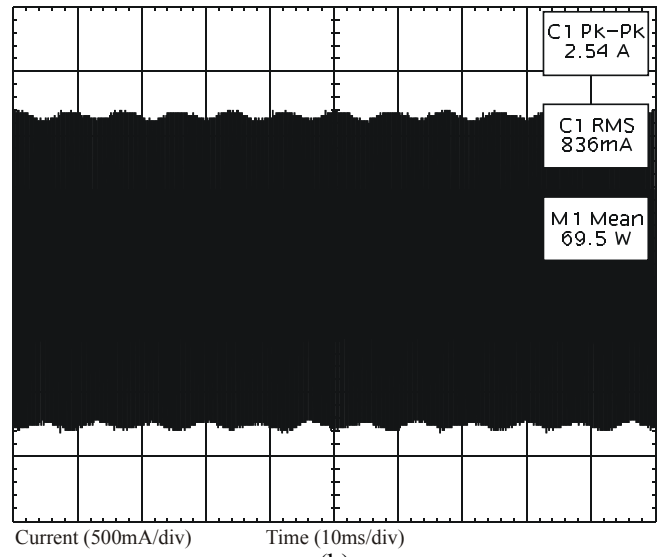

(b)

Fig. 9. Ballast waveforms for a new lamp. (a) Voltage and current of the lamp at high frequency. (b) Low frequency current through the lamp.

The measured line current harmonics are presented in Fig. 11. Each measured harmonic component meets the IEC 61000-3-2 Class C requirements.
As the feedback control law operates in the switching frequency some experimental were done to prove that these variations on the switching period do not change the power factor and the crest factor in a significant way.

Table 1 shows some acquisitions which were done with two new lamps and two older lamps. This table validates the good behavior of the output power control of the proposed topology. In this case, the transistors used in the experimentation have higher $\mathrm{R}_{\mathrm{DSon}}$ (IRF22N60K ) reducing the efficiency. The results showed in Fig. 8 and Fig. 9.

During the experimentations, the acoustic resonance was not detected mainly because the power control loop changes the switching frequency if the load changes, which is one of the consequences when the acoustic resonances occurs.

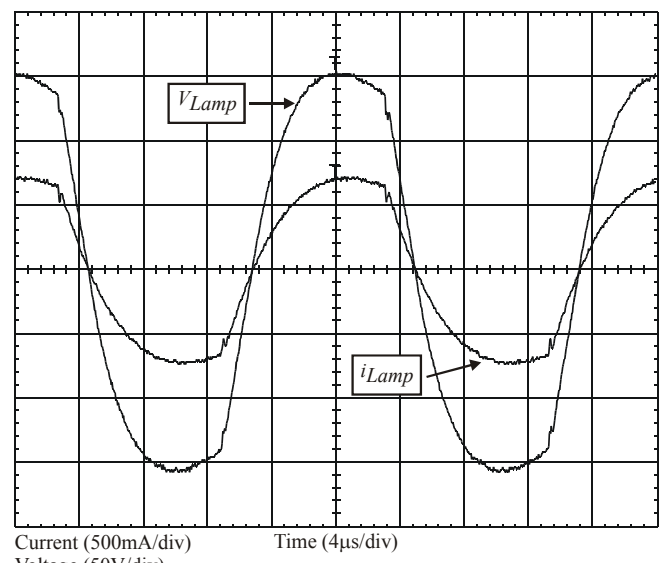

(a)

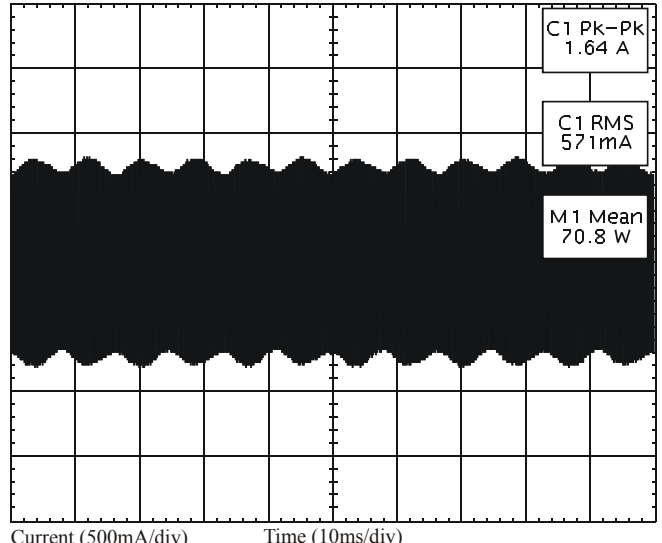

(b)

Fig. 10. Ballast waveforms for an old lamp. (a) Voltage and current of the lamp at high frequency. (b) Low frequency current through the lamp.

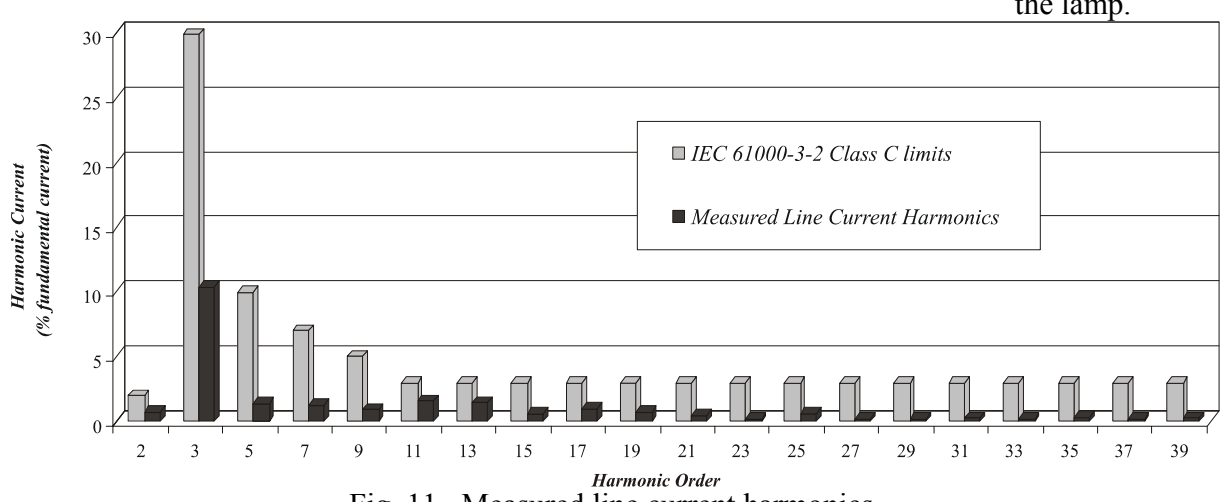

Fig. 11. Measured line current harmonics. 
TABLE 1. Comparison between the operation of the ballast with new lamps and old lamps.

\begin{tabular}{|c|c|c|c|c|}
\hline & $\begin{array}{c}\text { New } \\
\text { Lamp 1 }\end{array}$ & $\begin{array}{c}\text { New } \\
\text { Lamp 2 }\end{array}$ & Old Lamp 1 & Old Lamp 2 \\
\hline Source Power & $79.33 \mathrm{~W}$ & $79.44 \mathrm{~W}$ & $78.95 \mathrm{~W}$ & $80.64 \mathrm{~W}$ \\
\hline Lamp Power & $70.94 \mathrm{~W}$ & $71.89 \mathrm{~W}$ & $72.26 \mathrm{~W}$ & $73.22 \mathrm{~W}$ \\
\hline Efficiency “ $\eta$ ” & $89.43 \%$ & $90.52 \%$ & $91.47 \%$ & $90.79 \%$ \\
\hline Lamp Voltage & $71.67 \mathrm{~V}$ & $88.21 \mathrm{~V}$ & $108.7 \mathrm{~V}$ & $122.3 \mathrm{~V}$ \\
\hline Lamp Current & $994.5 \mathrm{~mA}$ & $820.8 \mathrm{~mA}$ & $669.4 \mathrm{~mA}$ & $606.5 \mathrm{~mA}$ \\
\hline Crest Factor & 1.552 & 1.524 & 1.583 & 1.572 \\
\hline Voltage THD & $3.472 \%$ & $3.413 \%$ & $3.340 \%$ & $3.558 \%$ \\
\hline Current THD & $11.996 \%$ & $13.075 \%$ & $13.009 \%$ & $14.080 \%$ \\
\hline Power Factor & 0.990 & 0.990 & 0.989 & 0.989 \\
\hline
\end{tabular}

\section{CONCLUSION}

A single-stage charge-pump voltage-source electronic ballast with unity power factor was presented. The proposed electronic ballast combines a PFC stage and an inverter stage in one topology to drive the HPS lamp. The topology was analyzed in detail. This analysis was done in two stages. The first stage analyzed the PFC stage. It was shown that with a proper high frequency input filter unity power factor can be achieved and that the input current is at twice the switching frequency, reducing the magnetic elements. In the second stage, the half bridge inverter was analyzed and a design methodology was presented. A microprocessor was used to generate the pulse signals that drive the switches and control the power of the lamp. This control system adjusts the switching frequency in a way to obtain constant output power. This control system guarantees constant lamp power, low THD and low crest factor when the lamp ages and when the input voltage oscillates. Therefore, this topology can be improved with special functions due to the microprocessor, which include lamp turn on at the beginning of the night and lamp turn off at the end of the night, dimmering the lamp at times when lower power is sufficient, thus saving electricity, and ballast protection in the case of a broken lamp or start-up failure. Additionally the proposed electronic ballast may provide high energy efficiency and low cost when compared to the conventional HPS electronic ballast.

\section{REFERENCES}

[1] C. Blanco, M. Alonso, E. López, A. Calleja, and M. Rico, “A single stage fluorescent lamp ballast with high power factor", IEEEAPEC, pp. 616-627, 1996.

[2] H. L. Do, and B. H. Kwon, "Single-stage line-coupled halfbridge ballast with unity power factor and ripple-free input current using a coupled inductor", IEEE Trans. Industrial Electron., vol. 50, pp. 1259-1266, Dec. 2003.

[3] J. H. Youm, H. L. Do, and B. H. Kwon, "A single-stage electronic ballast with high power factor", IEEE Trans. Industrial Electron., vol. 47, pp. 716-718, June 2000.

[4] J. Qian, F. C. Lee, T. Yamauchi, "New continuous-input current charge-pump power-factor-correction electronic ballast" IEEE Trans. Industrial Electron., vol. 35, pp. 433-441, March/April 1999.

[5] E. I. Pereira, C. B. Nascimento, A. J. Perin, "Electronic ballast for fluorescent lamps with the PFC stage integrated with the resonant inverter", 35th Annual IEEE Power Electron. Specialists Conference, vol. 5, pp. 4050-4056, June 2000.

[6] J. A. Alves, A. J. Perin, I. Barbi, "An electronic ballast with high power factor for compact fluorescent lamps", IEEE Industry Applications Conference, vol. 4, pp. 2129-2135, October 1996.

[7] T. Yamauchi, T. Shiomi, "A novel charge pump power factor correction electronic ballast for high intensity discharge lamps". IEEE Power Electronics Specialists Conference, pp. 1761-1767, 1998.

[8] H. L. Do, K. W. Seok, B. H. Won, "Single-Stage Electronic Ballast with Unity Power Factor". IEE Proc. Electr. Power Application, vol 148, n2, pp. 171-176, March, 2001.

[9] C. B. Nascimento, A. J. Perin, E. I. Pereira, "Low Cost High Power Factor Electronic Ballast with no Input Filter", IEEE Power Electronics Specialists Conference, pp. 1100-1106, 2005.

[10] C. B. Nascimento, J. M. Buttendorf, E. I. Pereira, A. J. Perin, "Reator Eletrônico com Circuito Simétrico para Correção do Fator de Potência”, XV Congresso Brasileiro de Automática, 2004.

[11] J. Qian, F. C. Lee, T. Yamauchi, "New continuous-input current charge-pump power-factor-correction electronic ballast", IEEE Trans. Industrial Electron., vol. 35, pp. 433-441, March/April 1999.

[12] J. H. Youm, H. L., Do, and B. H. Kwon, "A single-stage electronic ballast with high power factor", IEEE Trans. Industrial Electron., vol. 47, pp. 716-718, June 2000.

[13] J. F. Dums - "Single-Stage Voltage-Source ChargePump HPF Electronic Ballast for HPS Lamps" (in Portuguese) M.Sc. dissertation, Federal University of Santa Catarina, Brasil, September 2005.

\section{BIOGRAPHIES}

José Flávio Dums was born in São Bento do Sul, SC, Brazil, on March $28,1980$. He received the B. E. degree the M. Sc. degree in electrical engineering from Universidade Federal de Santa Catarina, Florianopolis, SC, Brazil in 2003 and 2005, respectively. He joined the Industrial Automation Department at Faculdade de Tecnologia Tupy (FTT - SOCIESC - SC) in 2005 and is now engaged in education and research on power electronics analysis and design. Research interests include power electronics, power factor correction, electronic ballast to use with HID lamps and industrial automation systems based on power electronics.

Claudinor Bitencourt Nascimento was born in Tubarão, Santa Catarina, Brazil, in 1971. He received the B. E., M. S. and Ph.D. degrees in electrical engineering in 1994, 1996 and 2005, respectively, from the Universidade Federal de Santa Catarina, Florianopolis, SC, Brazil. He joined the Electronic Coordination at Universidade Tecnológica Federal do Paraná (UTFPR) in 1997 where is currently acting as professor of power electronics and automation and control. Research interests include electronic ballasts for discharge lamps, power-factor-correction circuits and new converter topologies.

Arnaldo José Perin was born in Nova Prata, RS, Brazil, in 1953. He received the B.E. degree in electronic engineering from the Pontificia Universidade Catolica do Rio Grande do Sul, Brazil in 1977, the M. Sc. degree in electrical engineering from Universidade Federal de Santa Catarina, Florianopolis, SC, Brazil in 1980. In 1984 he received the Doctor Engineer degree (Dr. Ing.) from the Institut National Polytechnique de Toulouse (INPT), Toulouse, France. He joined the Electrical Engineering Department at Universidade Federal de Santa Catarina (UFSC) in 1980 and is now engaged in education and research on power electronics analysis and design. Research interests include power electronics, modulation, ac converters and power factor correction. Since 1993 the research interest concentrates more specifically on electronic ballast to use with fluorescent lamps and with HID lamps. In this area many research was published in Brazilian and International conferences. 